\title{
End-Of-Life Decision Making
}

\section{A Qualitative Study of Elderly Individuals}

\author{
Kenneth E. Rosenfeld, MD, Neil S. Wenger, MD, MPH, Marjorie Kagawa-Singer, PhD
}

OBJECTIVE: To identify the desired features of end-of-life medical decision making from the perspective of elderly individuals.

DESIGN: Qualitative study using in-depth interviews and analysis from a phenomenologic perspective.

SETTING: A senior center and a multilevel retirement community in Los Angeles.

PARTICIPANTS: Twenty-one elderly informants (mean age 83 years) representing a spectrum of functional status and prior experiences with end-of-life decision making.

MAIN RESULTS: Informants were concerned primarily with the outcomes of serious illness rather than the medical interventions that might be used, and defined treatments as desirable to the extent they could return the patient to his or her valued life activities. Advanced age was a relevant consideration in decision making, guided by concerns about personal losses and the meaning of having lived a "full life." Decisionmaking authority was granted both to physicians (for their technical expertise) and family members (for their concern for the patient's interests), and shifted from physician to family as the patient's prognosis for functional recovery became grim. Expressions of care, both by patients and family members, were often important contributors to end-of-life treatment decisions.

CONCLUSIONS: These findings suggest that advance directives and physician-patient discussions that focus on acceptable health states and valued life activities may be better suited to patients' end-of-life care goals than those that focus on specific medical interventions, such as cardiopulmonary resuscitation. We propose a model of collaborative surrogate decision making by families and physicians that encourages physicians to assume responsibility for recommending treatment plans, including the provision or withholding of specific life-sustaining treatments, when such recommendations are consistent with patients' and families' goals for care.

KEY WORDS: advance care planning; aged; decision making; life-sustaining treatment; physician-patient relations; proxy; terminal care.
J GEN INTERN MED 2000;15:620-625.

$\mathbf{T}$ here is intense public and professional interest in improving medical decision making near the end of life. ${ }^{1}$ When a patient's prognosis for meaningful survival is poor, physicians' traditional goals to preserve life, benefit patients, and respect patient autonomy often conflict. Contemporary ethics, law, and public policy have prioritized patient self-determination in these situations, ${ }^{2-4}$ affirming patients' right to refuse medical treatments and to complete advance directives. ${ }^{5}$

Research evidence, however, suggests that current practice falls far short of the ethical ideal of selfdetermination. Patients often lack sufficient knowledge of health states, interventions, and prognoses ${ }^{6-8}$ to make informed treatment choices. Advance directives, widely promoted as a means of extending self-determination to future states of mental incapacity, ${ }^{4}$ have been largely ineffective in clinical practice. ${ }^{9}$ Family members, felt to be in the best position to know patients' values and preferences, ${ }^{5}$ have been found to understand patients' treatment preferences little better than would be expected by chance. ${ }^{10-12}$ These and other difficulties with end-of-life decision making became glaringly apparent when the Study to Understand Prognoses and Preferences for Outcomes and Risks of Treatments (SUPPORT), a large intervention trial designed to improve end-of-life care failed to have any impact on physicians' knowledge of patients' treatment wishes or on the aggressive end-of-life treatments patients received. ${ }^{13}$

The disparity between contemporary ethical standards and actual clinical practice may be a marker of poor quality in end-of-life care. Alternatively, it could suggest that ethical standards do not fully capture patients' own goals for decision making during serious illness. We designed a qualitative study to identify the values that shape elderly individuals' attitudes about life-sustaining treatments and their patients' perspectives on decisionmaking authority during serious illness. Identifying contradictions between current ethical standards and patients' own goals may help physicians to facilitate end-of-life decision making with patients and families.

\section{METHODS}

Received from the Division of General Internal Medicine, Veterans Administration Greater Los Angeles Healthcare System, Los Angeles, Calif (KER); Department of Medicine, University of California, Los Angeles School of Medicine, Los Angeles, Calif (NSW); and University of California, Los Angeles School of Public Health and Asian-American Studies, Los Angeles, Calif (MK-S).

Address all correspondence and reprint requests to Dr. Rosenfeld: Division of General Internal Medicine (111G), VAGLAHS-WLA, 11301 Wilshire Blvd., Los Angeles, CA 90073 (e-mail: kenneth.rosenfeld@med.va.gov).

\section{Design}

The study employed in-depth interviews and a phenomenologic perspective. ${ }^{14}$ Qualitative methods are increasingly being used to build models for patient-centered care, and are often superior to quantitative approaches when questions about meaning or human values are explored. ${ }^{15}$ Phenomenology focuses on identifying the systems of meaning by which individuals make sense of their lives. This perspective was felt to be the most appropriate 
to investigate how patients and families approach end-oflife decision making.

\section{Setting, Participants, and Interview Structure}

We interviewed 21 elderly individuals from 2 sites in the Los Angeles area. Fourteen independent-living elderly, all of whom had 1 or more chronic health conditions, were recruited from a local senior center. Seven informants with a greater level of functional impairment (ranging from near-independent living to dependency for all instrumental activities of daily living) were selected from a multilevel retirement community. The sampling strategy was purposeful, using key informants (senior center staff, retirement community nurses, and social workers) to identify study participants differing in health status and prior experiences with end-of-life decisions. All study informants were screened to be cognitively intact prior to enrollment using the Mini-Mental State Examination (MMSE $\geq 27$ ). The mean age of study participants was 83 years old (range 72-92), nearly all were white (95\%), most were women (81\%) and widowed (74\%). Eighty-one percent had previously completed advance directives as both study sites had programs to encourage their use.

Interviews were in-depth and open-ended and lasted between 1 and 2 hours (average 75 minutes). Interviews were conducted by the principal investigator (KER) and most took place in informants' homes. The general interview framework was developed by end-of-life care experts (KER, NSW), an anthropologist (MK-S), and a psychologist, and was extensively piloted to identify relevant question areas. Interviews solicited informants' personal narratives of serious illness in themselves and others, and used probe questions to identify how decisions were made, who made them, and their outcomes. Clinical scenarios of serious illness were also used as an additional entree to informants' personal values regarding life-sustaining treatments, including their treatment preferences and how they assigned decision-making authority. These scenarios included a range of illnesses (advanced dementia, severe pneumonia), interventions (cardiopulmonary resuscitation [CPR], ventilator use), and prognoses. Often the scenarios overlapped considerably with informants' own experiences; in these situations, the scenarios were excluded from the interviews. The interview audiotapes were regularly reviewed by the principal investigator and anthropologist, who refined the probe questions to reflect themes that were emerging during data analysis.

\section{Data Analysis}

All interviews were audiotaped and transcribed verbatim, and were analyzed using content analysis techniques. ${ }^{16}$ One of 3 individuals, each of whom had graduate training in qualitative research, read each interview multiple times and wrote interpretations and comments about the text in the transcript margins. This coding pro- cess was accompanied by frequent team meetings during which the coded transcripts were reviewed and codes were compared across interviews to identify a common theme structure. Iterations of this process were used to refine the coding structure as subsequent interviews were conducted and new themes emerged, with earlier interviews being recoded to examine for the new themes.

"Trustworthiness" of the analysis, the qualitative equivalent of validity and reliability, ${ }^{15}$ was determined through 4 mechanisms: (1) theme saturation, which involved recruiting new informants into the study until 3 successive interviews yielded no new themes; (2) checks on intercoder reliability by independent coding of 3 interviews by 2 coders with comparison of coded themes, with reliability, which was $70 \%$ to $74 \%$, calculated as the number of text segments identified by both coders as relevant and assigned the same major theme divided by the total number of segments identified as important by either coder; (3) follow-up meetings with 3 of our informants during which we discussed our findings and sought respondent feedback; and (4) presentation to 2 physicians for clinical correlation with their own practice experience.

\section{RESULTS}

Analysis of the interview transcripts yielded 3 major themes: (1) the factors patients and families weigh in treatment decisions; (2) the manner in which individuals assign decision-making authority; and (3) the role of caring behaviors in end-of-life decision making.

\section{Factors Underlying Treatment Decisions}

Outcomes, not Treatments, Guide Treatment Preferences. Contrary to clinicians' current emphasis on identifying patient preferences for CPR and other specific life-sustaining treatments, informants emphasized the outcomes of such interventions rather than the interventions themselves. They identified a range of personal and interpersonal outcomes, including cognitive and physical function, self-care, productivity, and emotional or caretaking burden on loved ones. Foremost, they judged medical interventions as desirable if they could return a patient to his or her most valued life activities, as expressed by one 84-year-old woman:

Will he be able to get anything out of life? Will he be able to talk to his grandson, can he read the newspaper that he likes, and can he watch the Crossfire on the television, the limited things that he does? That's a simple standard. . .

Informants often used dichotomies when discussing interventions, using terms such as natural/artificial and normal/heroic. However, these dichotomies were not rooted in characteristics of the treatments themselves, but on the treatments' likelihood of restoring valued life activities. One 92-year-old man, reflecting on his decision 
to withhold antibiotic treatment from his wife, who had severe Alzheimer's disease, noted:

\section{If you feel by extraordinary measures you would return her to so-called life, don't do it. . 'cause what life has she got to go back to, except sitting here. . . in a most un- dignified way having her ass wiped and wearing a dia- per and listening to the screams of the other patients. And this is not the kind of life that my wife would have liked. And so don't do anything in the case she gets bronchitis or pneumonia, which is prone to keep her alive.}

To this informant, his wife's illness had rendered her incapable of gaining any enjoyment out of life. Given the certainty that the outcome of any further illness was at best, only a return to that state, he regarded any treatment that would prolong life (including antibiotics) as "extraordinary." Similarly, when asked to elaborate on her description of a treatment as "extraordinary" one 84-yearold woman's exclusive focus on functional outcomes became evident:

\footnotetext{
If the chances. . . for success are so small that it's not worth it, because the negative part of it is so great. . . if a person is gonna take a $10 \%$ chance that you're gonna ... know what's going on, and a 90\% chance that you're not going to be able to function normally, that's [extraordinary].
}

By comparison, an 86-year-old man who had completed a living will stating his desire that no "artificial" means be used to prolong his life, nevertheless expressed his preference to receive ventilator treatment in case of a potentially reversible pneumonia:

[a treatment would be artificial only] in the case of. . . prolonging my life after death. But [the doctor] is only bridging me between how I was before my getting the respirator to allow me to breathe so I can become conscious again.

This informant believed that the use of a ventilator was "artificial" only if it failed to restore his former health state. Despite his wish not to receive "artificial" end-of-life interventions, he classified the temporary use of a ventilator as a "normal" treatment.

\section{Advanced Age Is Relevant in Patients' Treatment} Considerations. Nearly all informants regarded their advanced age as relevant to treatment decision making. They focused in particular on 3 aspects of age-related decline: personal losses experienced in old age and the fear of future losses; the perception that serious illness in old age carries a poor prognosis; and the role which having lived a natural life span shaped one's perspective on lifethreatening illness.

Personal losses in old age. Individuals reflected on significant personal losses they had experienced including the death of spouses and other loved ones as well as losses of physical and sensory function. They also were concerned that future serious illness would continue or hasten that decline. One 89-year-old woman commented:
When you're between 60 and 70 you think you still have 20,30 years in front of you, and you want to do everything to get those 20 years. But if you are nearly 90 , you will get slower and slower in everything, and it's not so important anymore. Now, even if I fight it through, I don't see much fun in life, after you're sick.

A 92-year-old informant, having observed the decline and death of many of his peers, discussed its impact on his own preferences for life-prolonging treatments:

I see. . the daily deterioration of people. . people going from walking to the walker to the wheelchair, and then finally over to the hospital. . . given my druthers at a certain point in that,. . . I would prefer to go rather than to see that I was taking that same route. . .

Natural life span. Many individuals discussed advanced age in terms of the meaning they assigned to having lived a natural life span. They felt that having lived "a long life" led them to place more importance on maintaining function than on longevity per se. This perspective was particularly evident in a hypothetical scenario of serious illness, in which informants asked specifically about the patient's age in their deliberations. The following quotes exemplified the feelings expressed:

Well, a younger adult has a lot of life before them. . . their dreams and everything else. An elderly person has pretty much. . . lived her life. . . . I feel I have lived my life, I'm old enough now it doesn't. . really matter, you know. I want health of course. . . but if I die. . . it's not that big a thing.

I wouldn't want to pull a tube on a young person, no. But a person my age, yes, I would. . . . They have their whole life ahead. . . unless they're brain dead, or something, that's different.

Having gone through illnesses and pain, I would not wanna go through a lot of that later on down the line, because I know my age is a determining factor. . . Twenty years ago. . . I had not experienced much pain. But I have experienced pain now. And unless it could be something that could be alleviated, I wouldn't want to go through a lot of it.

For many informants, the combination of their concerns about current and future decline, along with their perception of having lived a full, long life led them to be less willing to tolerate the risks of pain and functional loss that life-threatening illness might bring.

\section{Decision-Making Authority}

The second theme included statements about decision-making authority in end-of-life treatment decisions. Informants assigned authority to both physicians and family members, based on their respective areas of expertise. Physicians were given authority based on their technical expertise in prognostication and treatment, and families were granted authority based on their primary concern for the patient's well-being. Informants assumed that the doctor and family members would collaborate, blending the physician's technical abilities with family 
caring to fulfill patients' own wishes, as discussed by one 82-year-old woman:

Well, \# 1 professionally my doctor. .. I would trust him. . . forever, and my husband for what would be best for me. . . . my doctor would use his head and my husband would use his heart.

The basis for family and physician authority led many informants to transfer decision-making authority from physicians' technical expertise to family members' caring when the patient's prognosis for functional recovery became poor. One 78-year-old woman and another 85-year-old woman expressed this shifting authority:

\begin{abstract}
[the doctor should make decisions] if it's not a situation where the person is practically dying. . . if there's a situation of treatment and health and things. . but. . . when it comes to prolonging the life unnecessarily, I think the family should have the decision to make.
\end{abstract}

[If] the doctor could prove that by extending whatever they're doing it will definitely cure that person or make them awake again. ... Otherwise it seems to me it's the family's loss. . . if they say that it's time to let go then it's time to let go.

Informants felt that the physician's skill in treating serious illness and prognosticating outcomes is critical to his or her decision-making authority. However, when functional recovery is not possible, the family's decisionmaking authority assumes precedence, aided by the doctor's support and technical guidance.

\section{Importance of "Caring" During Serious Illness}

The third theme included descriptions of caring behaviors and the role they play in end-of-life decision making. References to acts of caring-by families, by physicians and other caretakers, and by patients themselves-permeated the narratives and were often important contributors to end-of-life treatment decisions. Yet patients' and families' desire to care led them to very different viewpoints regarding end-of-life decisions. For patients, interpersonal caring included a desire not to burden their loved onesphysically, emotionally, or financially:

... I have had friends whose daughters or sons. . have just been subjected to terrible. . I would hate to be any kind of burden to anyone. . . I would hate to have to be subjected to that.

. . . why spend 500 dollars a day on a vegetable? Use it for the living.

On the other hand, for families caring meant the responsibility and desire to provide care for a seriously ill loved one. This caring could be manifest as physical or emotional caretaking, as noted by an 80-year-old woman:

I remember my grandmother. . . we fed her as much as she could eat and what she couldn't eat, well, this was the way it was done. . . you tried as much as you can to let her eat. . . . It was a few days and then she died. I would rather see that than a prolongation of it.
In situations where family members could not guarantee such physical caretaking, however, caring might be substituted with the provision of life-prolonging medical treatments. In contrast with the care her family had given her grandmother, the same 80-year-old informant reflected on the end-of-life care her mother received in a nursing home. She acknowledged that her mother would never have wanted to be artificially fed, yet she elected to place a feeding tube in her nursing home-bound mother. The informant expressed that tube feeding was a poor substitute for the end-of-life caring that manual feeding would have provided:

\begin{abstract}
... in the [nursing home] the nurses don't always have time. . . the feeding is terrible. . . if she was home and I was feeding her as well as I could and she was doing as well as she could and that stopped, it's sad and it hurt alright but. . . I don't know. . . I would prefer that she could have been [hand] fed.
\end{abstract}

\section{DISCUSSION}

Analysis of these elderly informants' narratives revealed several clinically important findings that contradict current clinical practice. First, in decision making during serious illness, patients focus on outcomes, not treatments. To our informants, specific interventions such as CPR or mechanical ventilation were largely irrelevant beyond the ability of these treatments to restore patients' valued life activities. Patients' outcomes orientation contrasts sharply with physicians' own focus on patients' preferences for specific life-sustaining treatments, as they seek to ascertain patients' "code status." Such disparate orientations may explain the difficulties providers experience in endof-life discussions with their patients. Our findings also suggest that highly specific advance directive documents, in which patients are asked to choose from a checklist of many possible interventions in a variety of illness scenarios, ${ }^{17}$ may not match patients' own models of end-of-life planning. Our informants' perspectives were more closely aligned with an approach that identifies patients' most valued life activities or "states worse than death."18,19 These outcomes-oriented formats, designed to clarify health states in which any life-prolonging medical treatments would be unacceptable, appeared to provide a better match to informants' end-of-life objectives.

The role of advanced age in end-of-life decisions has been the subject of considerable debate. Age per se has been inconsistently associated with survival after $\mathrm{CPR}^{20-23}$ or other interventions used in serious illness, ${ }^{24-29}$ yet studies have consistently shown that elderly patients receive less aggressive treatment for many illnesses, including breast cancer, ${ }^{30,31}$ coronary artery disease, ${ }^{32}$ and acute critical illness. ${ }^{33}$ The discrepancy between treatment outcomes and the provision of such treatments has been attributed to age bias on the part of providers ${ }^{31,33}$; alternatively, it may reflect a disparity between the preferences of elderly and younger patients for aggressive life-sustaining 
care. ${ }^{34}$ The informants in this study, who largely represent the "oldest old," felt that advanced age was an important contributor to their own treatment preferences. The meaning they assigned to old age reflected concerns over their current health state and future decline, the deaths of significant loved ones, and the personal significance of having lived a "natural life span." While these concerns may not be important to all elderly individuals facing treatment decisions, they led most of our informants to be less willing to risk substantial suffering or functional loss for the opportunity to live longer.

Some experts have argued that assigning decision-making authority to a proxy is an even more important element of advance planning than is documenting one's advance wishes. ${ }^{35}$ We found that authority is granted both to family members, based on their concern for patients' interests, and physicians, for their technical expertise. Our findings are consistent with other studies reporting patients' strong desire to have family members as proxies in end-of-life decisions, ${ }^{36,37}$ even granting them substantial leeway to override patients' own advance treatment wishes. ${ }^{38}$ They also match the findings from several studies examining authority preferences in cancer treatment decisions, where up to $60 \%$ percent of cancer patients preferred that their doctor make the final treatment decisions. ${ }^{39-41}$

The model for dual authority identified in this study, however, contrasts both with historic models for end-oflife decision making that embraced a paternalistic perspective and contemporary legal standards that do not grant any formal authority for physicians. Our data suggest that patients' goals may be achieved best by a model of collaborative surrogate decision making by families and physicians. Families can represent patients' interests by defining acceptable outcomes and delineating goals of care based on their understanding of patients' values. Physicians can be responsible for providing accurate prognostic information, for outlining a range of achievable goals of care, and for making specific recommendations to use or withhold curative treatments based on mutually defined goals.

Our inquiry also found that expressions of carepatients' concerns about burdening loved ones on the one hand, and caregiver obligations to ill family members on the other-are potent values in settings of poor prognosis. High $^{36,37}$ has reported extensively on families' filial expectations, and other authors have found that concerns about family burden are a principal reason that patients reject life-sustaining treatments. ${ }^{42}$ In another recent qualitative study, Singer et al. ${ }^{43}$ reported that acts of caring-relieving burden and strengthening relationships with loved onesare critical to patients' perceptions of quality end-of-life care.

The importance of family caring behaviors in settings of poor prognosis has important implications with regard to physician-family interactions in the care of mentally incapacitated patients. In situations where patients' survival is unlikely, physicians can support family authority by focusing decision making on caring behaviors, the family's primary domain. Support can be expressed for example, by seeking the family's perceptions regarding the role that nutrition and hydration might play as an expression of caring. Physicians can also assuage family members' feelings of guilt or abandonment by making explicit the types of comfort-oriented interventions that will be added when decisions are made to discontinue curative treatments.

The decision to use a qualitative approach for this study was made with an understanding of the trade-off between gaining an in-depth understanding of the research questions and the study's generalizability. Despite our efforts to assure the trustworthiness of our findings, the small size, advanced age, and ethnic and racial homogeneity of our study sample are limitations to its generalizability to other patient populations. In particular, the high rate of advance directive completion at both sites (through programs to encourage their use) may reflect that informants are not representative of the general population in whom advance care planning occurs much less frequently. In addition, because informants' personal experiences with endof-life decisions were retrospectively elicited, it is unclear whether their narratives represent clinical decision making as it actually occurred. Prospective studies conducted in actual decision-making settings may help to confirm our findings. Finally, this study focused on older individuals' perspectives as family members or as patients faced with serious illness. Physician perspectives, which are an integral part of any model for end-of-life decision making, were absent and should be pursued in future work.

\section{CONCLUSIONS}

Based on the findings of this qualitative study, we propose a revised model for advance directive discussions or end-of-life decision making with patients and/or families. First, rather than focus discussions on patients' desire for CPR or other life-sustaining treatments, clinicians would focus on the health states or probabilities for recovery which define "acceptable" illness outcomes; using this information, patients and physicians can define the goals for patients' future medical care. Physicians could then make recommendations as to which specific treatments would be reasonably likely to meet patients' goals, leading to further patient-physician dialogue (e.g., regarding patients' willingness to accept risks of poor outcomes). Second, while treatments would not be limited to the elderly on the basis of age alone, the personal meaning of advanced age and having lived a "full life" would be elicited from patients during advance planning discussions. Third, since doctors' authority is primarily grounded in their detailed knowledge of interventions and prognoses, physicians would be more willing to assume responsibility in recommending treatment plans, including the provision or withholding of specific lifesustaining treatments, in order to meet patients' and families' goals for care. Fourth, in situations where patients' prognosis for recovery is poor physicians would recognize the importance that caretaking behaviors play within families, 
and would actively support family members' desire to care for their dying loved one.

This research was partially funded by the Robert Wood Johnson Clinical Scholars Program. The views expressed above are those of the authors and do not necessarily reflect those of the Robert Wood Johnson Foundation.

\section{REFERENCES}

1. Rudberg MA, Teno JM, Lynn J. Developing and implementing measures of quality of care at the end of life: a call for action. J Am Geriatr Soc. 1997;45:528-30.

2. Childress JF, Beauchamp TL. Principles of Biomedical Ethics. 4th ed. New York, NY: Oxford University Press; 1994.

3. Cruzan v Director, Missouri Department of Health, 110 S Ct 2841 (1990).

4. Omnibus Budget Reconciliation Act (US Public Law 101-508), 1990.

5. President's Commission for the Study of Ethical Problems in Medicine and Medical and Behavioral Research. Deciding to Forego Life-Sustaining Treatment: Ethical, Medical, and Legal Issues in treatment Decisions. Washington, DC: US Government Printing Office; 1983.

6. Schonwetter RS, Walker RM, Kramer DR, Robinson BE. Resuscitation decision making in the elderly: the value of outcome data. $\mathrm{J}$ Gen Intern Med. 1993;8:295-300.

7. Murphy DJ, Burrows D, Santilli S, et al. The influence of the probability of survival on patients' preferences regarding cardiopulmonary resuscitation. N Engl J Med. 1994;330:545-9.

8. Miller DL, Jahnigen DW, Gorbien MJ, Simbartl L. Cardiopulmonary resuscitation: how useful? Attitudes and knowledge of an elderly population. Arch Intern Med. 1992;152:578-82.

9. Teno JM, Licks S, Lynn J, et al. Do advance directives provide instructions that direct care? SUPPORT Investigators. Study to Understand Prognoses and Preferences for Outcomes and Risks of Treatment. J Am Geriatr Soc. 1997;45:508-12.

10. Uhlmann R, Pearlman R, Cain KC. Physicians' and spouses' predictions of elderly patients' resuscitation preferences. J Gerontology. 1988;43:M115-21.

11. Hare J, Pratt C, Nelson C. Agreement between patients and their self-selected surrogates on difficult medical decisions. Arch Intern Med. 1992;152:1049-54.

12. Layde PM, Beam CA, Broste SK, et al. Surrogates' predictions of seriously ill patients' resuscitation preferences. Arch Fam Med. 1995;4:518-23.

13. A controlled trial to improve care for seriously ill hospitalized patients: the Study to Understand Prognoses and Preferences for Outcomes and Risks of Treatments (SUPPORT). The SUPPORT Principal Investigators. JAMA. 1995;274:1591-8.

14. Morse JM, ed. Qualitative Health Research. Newbury Park, Calif: Sage; 1992.

15. Inui TS. The virtue of qualitative and quantitative research. Ann Intern Med. 1996;125:770-1.

16. Patton M. Qualitative Evaluation and Research Methods. Newbury Park, Calif: Sage; 1990.

17. Emanuel L. The health care directive: learning how to draft advance care documents. J Am Geriatr Soc. 1991;39:1221-8.

18. Ditto PH, Druley JA, Moore KA, Danks JH, Smucker WD. Fates worse than death: the role of valued life activities in health-state evaluations. Health Psychol. 1996;15:332-43.

19. Patrick DL, Pearlman RA, Starks HE, Cain KC, Cole WG, Uhlmann $\mathrm{RF}$. Validation of preferences for life-sustaining treatment: implications for advance care planning. Ann Intern Med. 1997;127:509-17.

20. Berger R, Kelley M. Survival after in-hospital cardiopulmonary ar- rest of non-critically ill patients: a prospective study. Chest. 1994; 106:872-9.

21. Tresch D, Heudebert G, Kutty K, Ohlert J, VanBeek K, Masi A. Cardiopulmonary resuscitation in elderly patients hospitalized in the 1990s: a favorable outcome. J Am Geriatr Soc. 1994;42:137-42.

22. Schultz SC, Cullinane DC, Pasquale MD, Magnant C, Evans SR. Predicting in-hospital mortality during cardiopulmonary resuscitation. Resuscitation. 1996;33:13-7.

23. Cooper S, Cade J. Predicting survival, in-hospital cardiac arrests: resuscitation survival variables and training effectiveness. Resuscitation. 1997;35:17-22.

24. Leroy O, Santre C, Beuscart C, et al. A five-year study of severe community-acquired pneumonia with emphasis on prognosis in patients admitted to an intensive care unit. Intensive Care Med. 1995;2:24-31.

25. Markowitz JS, Pashko S, Gutterman EM, Linde-Zwirble WT, Newbold R. Death rates among patients hospitalized with communityacquired pneumonia: a reexamination with data from three states. Am J Public Health. 1996;86(pt1):1152-4.

26. Djaiani G, Ridley S. Outcome of intensive care in the elderly. Anaesthesia. 1997;52:1130-6.

27. Dardaine V, Constans T, Lasfargues G, Perrotin D, Ginies G. Outcome of elderly patients requiring ventilatory support in intensive care. Aging. 1995;7:221-7.

28. Olsson M, Granstrom L, Lindblom D, Rosenqvist M, Ryden L. Aortic valve replacement in octogenarians with aortic stenosis: a case-control study. J Am Coll Card. 1992;20:1512-6.

29. Cascinu S, Del Ferro E, Catalano G. Toxicity and therapeutic response to chemotherapy in patients aged 70 years or older with advanced cancer. Am J Clin Oncol. 1996;19:371-4.

30. Silliman RA, Guadagnoli E, Weitberg AB, Mor V. Age as a predictor of diagnostic and initial treatment intensity in newly diagnosed breast cancer patients. J Gerontology. 1989; 44:M46-50.

31. Greenfield S, Blanco DM, Elashoff RM, Ganz PA. Patterns of care related to age of breast cancer patients. JAMA. 1987; 257:2766-70.

32. Malone ML, Sial SH, Battiola RJ, Nachodsky JP, Solomon DJ, Goodwin JS. Age-related differences in the utilization of therapies post acute myocardial infarction. J Am Geriatr Soc. 1995; 43:627-33.

33. Boyd K, Teres D, Rapoport J, Lemeshow S. The relationship between age and the use of DNR orders in critical care patients. Evidence for age discrimination. Arch Intern Med. 1996;156:1821-6.

34. Phillips RS, Wenger NS, Teno J, et al. Choices of seriously ill patients about cardiopulmonary resuscitation: correlates and outcomes. Am J Med. 1996;100:128-37.

35. Lynn J. Why I don't have a living will. Law Med Hlth Care. 1991;19:101-4.

36. High DM, Turner HB. Surrogate decision-making: the elderly's familial expectations. Theoret Med. 1987;8:303-20.

37. High DM. All in the family: extended autonomy and expectations in surrogate health care decision-making. Gerontologist. 1988; 28(suppl):46-51.

38. Sehgal A, Galbraith A, Chesney M, Schoenfeld P, Charles G, Lo B. How strictly do dialysis patients want their advance directives followed? JAMA. 1992; 267:59-63.

39. Degner LF, Sloan JA. Decision making during serious illness: what role do patients really want to play? J Clin Epidemiol. 1992;45:941-50.

40. Davison BJ, Degner LF, Morgan TR. Information and decisionmaking preferences of men with prostate cancer. Oncol Nurs Forum. 1995;22:1401-8.

41. Degner LF, Kristjanson LJ, Bowman D, et al. Information needs and decisional preferences in women with breast cancer. JAMA. 1997;277:1485-92.

42. Zweibel NR, Cassel CK. Treatment choices at the end of life: a comparison of decisions by older patients and their physicianselected proxies. Gerontologist. 1989;29:615-21.

43. Singer PA, Martin DK, Merrijoy K. Quality end-of-life care: patients' perspectives. JAMA. 1999;281:163-8. 